\title{
Implementasi Aplikasi Manajemen Mes (AMM) Berbasis Web
}

\author{
Rahma Dwi Cahyani ${ }^{1}$, Hendrik Setyo Utomo ${ }^{2}$ \\ ${ }^{1,2}$ Teknologi Informasi, Politenik Negeri Tanah Laut, Tanah Laut, Indonesia \\ ${ }^{1}$ rahma.dwi.cahayni.99@gmail.com, ${ }^{2}$ hendrik.tomo@ politala.ac.id
}

Diterima 22 April 2020

Disetujui 19 Mei 2021

\begin{abstract}
The guesthouse management process of PT PPA is done conventionally, the Group Leader (GL) and the admin coordinate face to face for data collection or changes in employee data on the homestead dwellers. Temporary data collection is done by paper, then entered by MS. Excel. Reporting on homesteads is done by MS. Excel. If there is a change in data, then the reporting of the guest house is invalid. The researcher's goal is to implement a guesthouse management application to accommodate real-time data collection by the Group Leader. Reporting on the residents of the guesthouse can be done based on the date of the guesthouse management transaction. Testing is done by black-box testing and user acceptance test (UAT). All test results are functionally successful, and the test is carried out by the IT department. Based on the UAT test, the mes management application has an attractive appearance, is very easy to use, is very helpful for room relocation, is very in accordance with the proposed design, is very well organized by employees' rooms, is very suitable for the data entered and passwords can be hidden very well.
\end{abstract}

$\begin{array}{ccc}\text { Index } & \text { Terms-guesthouse; } & \text { homesteads; } \\ \text { management; } & \text { reporting; User Acceptance Test (UAT) }\end{array}$

\section{PENDAhUluan}

PT. Putra Perkasa Abadi Site BIB (Giri Mulya) (PT. PPA) merupakan perusahaan yang bergerak di bidang kontraktor dan jasa pertambangan batu bara yang sedang berkembang di Indonesia. PT. PPA terbagi menjadi beberapa site, salah satu operasi PT. PPA yaitu site BIB (Giri Mulya). PT. PPA yang terletak di daerah Mangkalapi, Kec. Kusan Hulu, Kab. Tanah Bumbu, Kalimantan Selatan.

PT. PPA terdiri dari beberapa department, salah satunya dept. Human Capital \& General Affair (HCGA). Human Capital \& General Affair (HCGA) adalah department yang bertugas berkoordinasi dengan Sumber Daya Manusia (SDM), Transportation, Information, Comunication and Technology, Corporate Social Responsibility and Eksternal (CSR) \& Security. PT. PPA memiliki berbagai fasilitas seperti foodcourt, gym, barbershop, PPAmart, studio musik, lapangan futsal, lapangan takraw, lapangan volly, lapangan badminton, tempat pemancingan dan memiliki ratusan mes (wisma) sebagai fasilitas tempat tinggal para karyawan tetap PT. PPA.

Mes merupakan tempat tinggal yang disediakan oleh perusahaan untuk karyawan. PT. PPA mendirikan mes dengan bangunan rumah yang terdiri dari banyak kamar. Rumah tersebut terdapat beberapa karyawan dengan masing-masing ranjang. Pendataan karyawan yang menempati mes dilakukan oleh admin atau karyawan departement HCGA. Proses pendataan dilakukan dengan konvensional yaitu menggunakan komputer dengan aplikasi Microsoft Excel.

Proses pendataan terdapat permasalahan yaitu pertama terdapat karyawan yang melakukan pindah kamar, pencatatan sementara hanya di kertas dan belum dilakukan perubahan data pada aplikasi Microsoft Excel. Kedua, pembuatan laporan penghuni mes dilakukan memerlukan waktu cukup lama, karena terjadi perubahan data yang belum berubah dalam aplikasi tersebut.

Solusi dari permasalahan tersebut yaitu rancang bangun aplikasi berbasis web responsif dengan basis data sebagai tempat penyimpanan data. Solusi tersebut dapat mengakomodir dari permasalahan yaitu terdapat perubahan data dapat dilakukan dengan menggunakan smartphone yang terhubung dengan jaringan lokal. Pelaporan dapat dilakukan sesuai dengan hasil yang diinginkan, karena data seluruhnya akan tersimpan dalam database.

Tujuan aplikasi manajemen mes adalah rancang bangun serta mengimplementasikan aplikasi manajemen mes berbasis. Manfaatnya yaitu membantu dan mengakomodir permasalahan manajeman mes PT. PPA dalam pengelolaan mes dari sistem konvensional menjadi sistem aplikasi (software).

\section{TEORI}

\section{A. Black Box Testing}

Artikel [1], [2] pengujian black box merupakan pengujian dilakuan secara fungsional dari suatu sistem. Pengujian black box dilakukan berdasarkan persyaratan pelanggan (customer's) dan dilakukan 
berdasarkan sudut pandang pengguna akhir (end user).

Menurut [2] pengujian black box memiliki keuntungan yaitu:

- Pengujian black box tidak perlu memiliki pengetahuan khusus dari bahasa pemrograman.

- Pengujian black box dapat dilakukan oleh seorang programmer dan penguji indenpenden (tester independent) satu dengan lainnya.

- Membantu memaparkan ambiguitas atau inkonsistensi dalam persyaratan spesifikasi dari pengguna.

\section{B. Pengujian User Acceptance Test}

User Acceptance Test (UAT) adalah fase terakhir dari proses pengujian perangkat lunak. Proses pemeriksaan apakah solusi tersebut sudah sesuai dengan kebutuhan user. UAT biasanya berfokus kepada fungsionalitas software dan detail teknis lainnya yang nantinya akan digunakan oleh user [3].

Tujuan UAT adalah untuk menilai apakah sistem dapat mendukung proses bisnis sehari-hari dan skenario user serta memastikan sistem sesuai alur proses bisnis [3].

\section{Kajian Penelitian yang Relevan}

Kajian penelitian pertama [4] yaitu dengan judul Sistem Reservasi Penginapan dengan Aplikasi Android (Studi Kasus PT. Chevron Pacific Indonesia). Hasil penelitiannya yaitu membangun suatu sistem reservasi pegawai dan pimpinan. Sistem reservasi memudahkan pegawai dan pimpinan dalam hal login sistem, approval pimpinan, data durasi tinggal dan memilih kama wisma. Sistem reservasi yang dibangun berbasis Android.

Penelitian yang kedua [5] yaitu dengan judul Aplikasi Penerapan Single Page Application Menggunakan Teknologi AJAX dan REST API (Sutdi Kasus: Sistem Informasi Reservasi Wisma Tamu UKSW). Hasil penelitiannya mengenai implementasi sistem informasi reservasi Wisma Tamu UKSW dengan menerapkan single page application dengan teknologi AJAX dan REST API. Manfaatnya yaitu dapat meningkatkan kualitas pelayanan ke pelanggan tamu UKSW.

Penelitian yang ketiga [6] yaitu dengan judul Aplikasi Reservasi Kamar Wisma Berbasi Web Studi Kasus: Penginapan Imbalo Group Rantau Parapat Sumatera Utara. Hasil penelitiannya yaitu membangun aplikasi reservasi kamar wisma berbasi website. Manfaat yaitu membantu pemesanan kamar secara online dan pegolahan data-data pada wisma Imbalo Group.
Penelitian yang keempat [7] yaitu dengan judul Perancangan Sistem Informasi Penginapan Berbasis Desktop di Penginapan A2hay Sorong Papua Barat. Manfaatnya yaitu membantu permasalahan dari pengolahan data tamu, data keuangan,, penggajian, pencarian data, dan pembuatan laporan dengan menggunakan aplikasi berbasis desktop Microsoft Visual Studio 2010.

Penerapan penulis lakukan saat ini yaitu membangun aplikasi manajemen mes berbasis web mobile dengan menggunakan framework laravel.

\section{HASIL PENELITIAN}

\section{A. Metode Pengembangan Sistem}

Metode yang digunakan dalam pengembangan perangkat lunak yaitu dengan waterfall. Model waterfall menggambarkan pendekatan yang sistematis dan berurutan (liniear) dalamsuatu perangkat lunak. Terlihat pada Gambar 1 merupakan model waterfall.

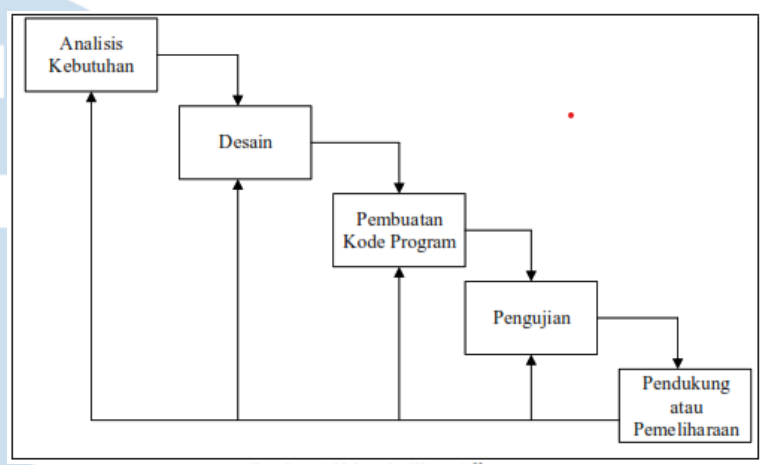

\section{Gambar 1. Model waterfall}

Sumber : [8]

1. Analisis Kebutuhan

Pengumpulan dalam analisis kebutuhan dalam pembangunan aplikasi manajemen mes adalah melakukan pengumpulan data dengan teknik wawancara dan teknik observasi kepada admin (Departement HCGA) dan hasil yang didapatkan seperti alur dari pengajuan menghuni mes dan kendalanya.

\section{Desain Sistem}

Proses desain perangkat lunak yaitu dengan membuat rancangan desain struktur data berupa: ERD, UML, dan representasi antarmuka.

3. Penulisan Kode Program

Desain diterjemahkan dengan menggunakan kode program PHP, HTML, CSS dan framework laravel. 
4. Pengujian Program

Pengujian menggunakan black box testing oleh user yaitu pengguna pada perusahaan PT. PPA. Pengujian dilakukan dari awal pembangunan aplikasi manajemen mes.

5. Pendukung dan Pemeliharan

Program yang telah diuji, jika ada terjadi update atau perbaikan pada sistem yang telah dibangun, maka akan dilakukan tindakan pemeliharan. Pada tahapan ini kita dapat mengulangi proses pengembangan mulai dari analisis kebutuhan, namun tidak membuat perangkat lunak yang baru.

\section{B. Analisis Sistem yang Berjalan}

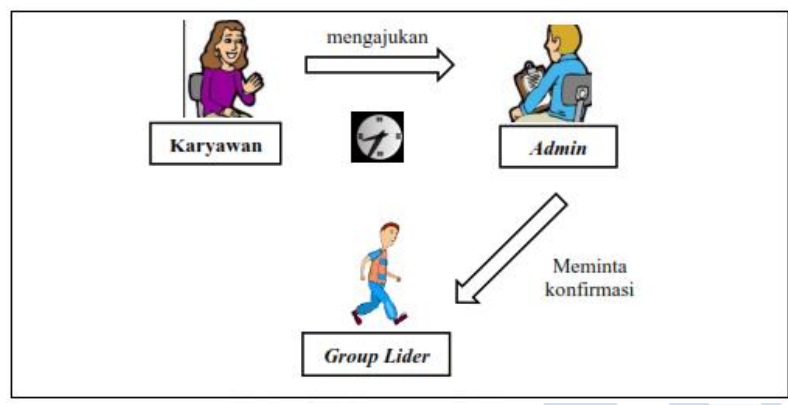

Gambar 2. Sistem yang berjalan

Gambar 2 merupakan analisis sistem yang sedang berjalan yaitu:

- Karyawan melakukan pengajuan menempati mes kepada admin.

- Admin akan melakukan komunikasi dan kornfirmasi terlebih dahulu ke bagian Group Leader $(G L)$ (Pimpiman Bagian) pada Genereal Service.

- $G L$ melakukan konfirmasi kepada admin untuk karyawan yang akan menempati mes.

- Alur terakhir yaitu admin memasukkan data karyawan yang akan menempati mes.

\section{Analisis Sistem yang Diusulkan}

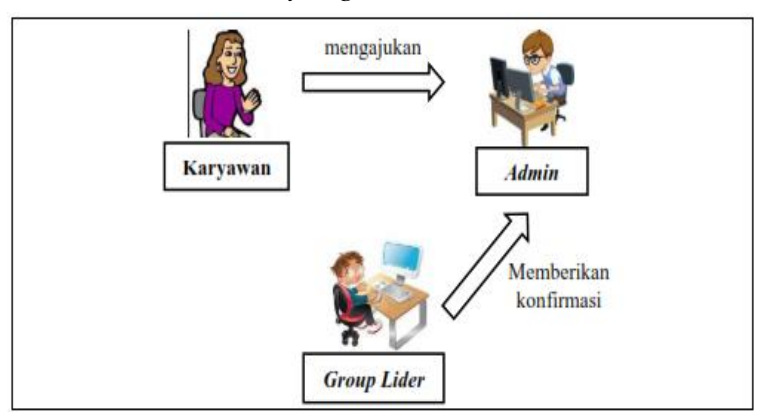

Gambar 3. Sistem yang diusulkan
Gambar 3 merupakan analisis sistem yang diusulkan berupa:

- Karyawan melakukan pengajuan kepada admin

- Admin akan mencari informasi mes melalui aplikasi dan data mes telah terbaru dari GL. Selanjutnya yaitu pendataan melalui karyawan melalui aplikasi manajemen mes.

- Admin dapat mengetahui dan melaporkan formasi lengkap dari palikasi manajemen mes.

\section{HASIL DAN PEMBAHASAN}

\section{A. Entity Relationship Diagram (ERD)}

Rancangan ERD aplikasi manajemen mes berbasis web terdapat 8 entitas (tabel). Tabel tersebut yaitu karyawan, transaksi_kamar, kamar, mes_type, user, user_role, perusahaan dan t_dept. Hubungan atau relasi antar tabel memiliki cardinality yaitu 1 to 1 sebanyak 1 relasi, 1 to many sebanyak 5 relasi dan terdapat 1 tabel yang tidak berelasi yaitu tabel perusahaan.

\section{B. Use Case Diagram}

Use Case Diagram memaparkan bagaimana aliran masukan dan keluaran dari sistem yang dibangun. Use Case Diagaram memiliki 2 aktor yaitu aktor pimpinan department dan staff (pengelolaan data mes dan karyawan PT. PPA). Aktor pimpinan department hanya melakukan monitoring terhadap sistem yang berjalan. Aktor staff melakukan seluruh transaksi untuk aktivitas mes dan karyawan.

\section{Implementasi Menu Login}

Desain halaman login menampilkan nama username dan password yang harus diisi Admin atau Super Admin terlebih dahulu agar dapat mengakses halaman selanjutnya.

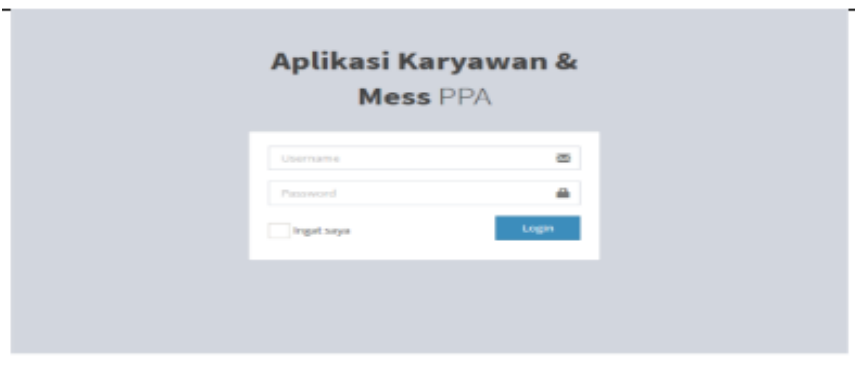

Gambar 4. Menu login

\section{Implementasi Bentuk Data Kamar}

Menu data kamar merupakan pengelolaan kamar tersedia (kamar kosong) atau tidak tersedia (kamar tidak kosong). 


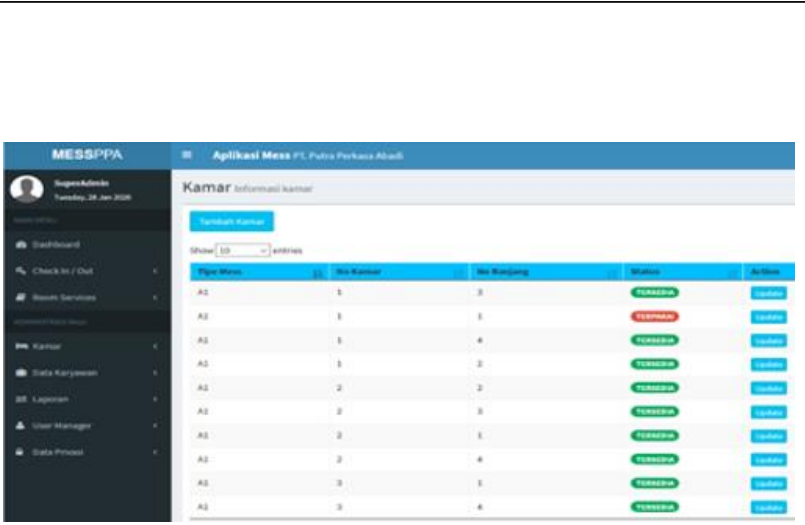

Gambar 5. Menu data kamar

\section{E. Implementasi Menu Check In dan Check Out}

Menu data Check In dan Check Out merupakan menu untuk memasukkan karyawan yang tinggal di mes dan pindah atau keluar karyawan dari mes.

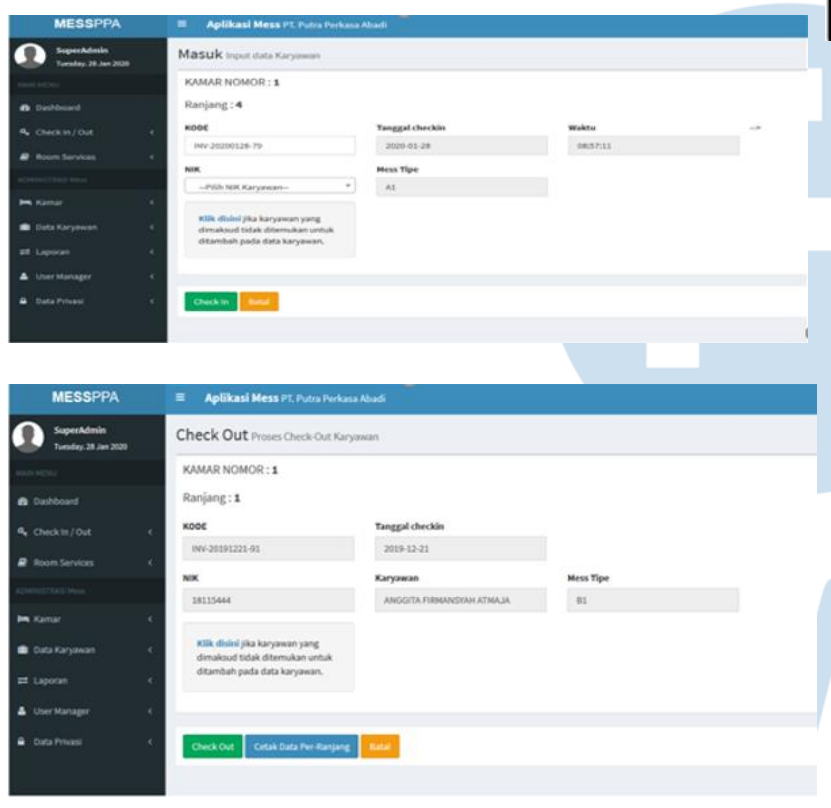

Gambar 6. Menu check in dan check out

\section{F. Pengujian Black Box}

Pengujian Black Box pada aplikasi manajemen mes oleh IT Programmer HCGA, PT. PPA. Seluruh fungsional pada aplikasi dilakukan pengujian Black Box. Hasil pengujian Black Box yaitu berhasil seluruh fungsional pada aplikasi manajemen mes. Berikut merupkan ditampilkan pada Tabel 1 dan Gambar 7 merupakan salah fungsi pengujian Black Box.

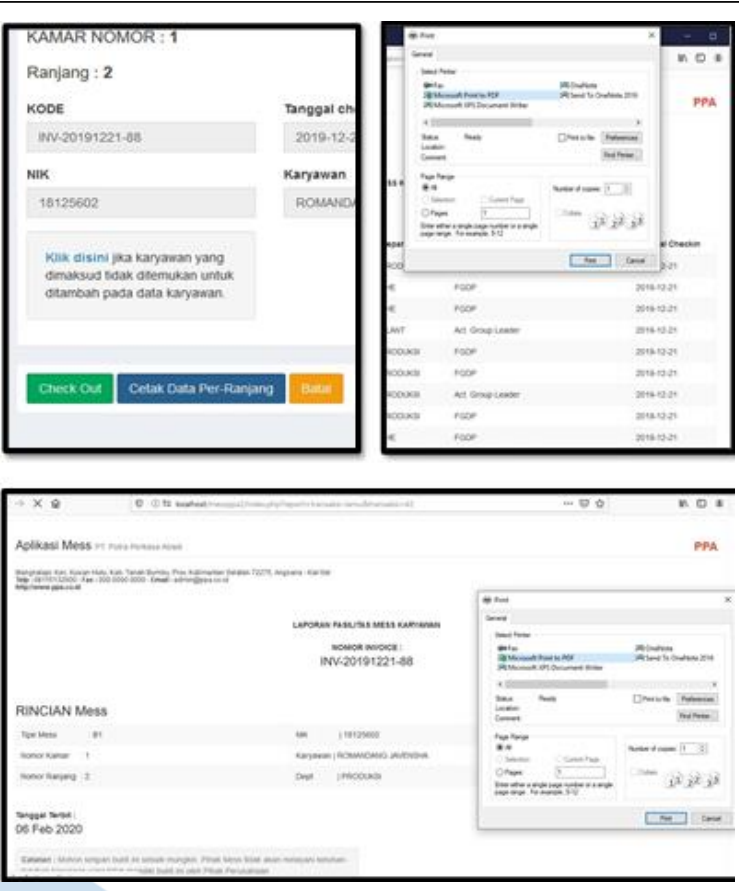

Gambar 7. Hasil pengujian Black Box

Tabel 1. Skenario dan hasil pengujian Black Box

\begin{tabular}{|c|c|c|c|c|}
\hline \multicolumn{5}{|c|}{ Kasus Dan Hasil Uji } \\
\hline $\begin{array}{c}\text { Data } \\
\text { Masukan }\end{array}$ & Diharapkan & Pengamatan & Kesinpulan & Gambar \\
\hline \multirow{2}{*}{$\begin{array}{c}\text { Klik Tombol } \\
\text { Cetak }\end{array}$} & $\begin{array}{c}\text { Menampilkan } \\
\text { data cetak }\end{array}$ & $\begin{array}{c}\text { Menampilkan } \\
\text { hasil cetak } \\
\text { data }\end{array}$ & [*] diterima & Gambar 7 \\
\hline & $\begin{array}{c}\text { Dapat kembali } \\
\text { ke tampilan } \\
\text { sebelumnya. }\end{array}$ & $\begin{array}{l}\text { Kembali ke } \\
\text { tampilan } \\
\text { sebelumnya }\end{array}$ & $\begin{array}{l}\text { [*] diterima } \\
{[\text { ] ditolak }}\end{array}$ & Gambar 7 \\
\hline
\end{tabular}

\section{G. User Acceptance Test (UAT)}

Aplikasi manajemen mes memiliki dua level akun yaitu akun user untuk staff departemen HCGA sebagai Admin mes dan akun user untuk Dept. Head HCGA sebagai kepala departemen, yang mana dua akun user tersebut telah memberikan hasil uji kelayakan aplikasi manajemen mes.

Bobot nilai jawaban memiliki 5 kategori jawaban yaitu:
A. Sangat: Mudah/Bagus/Sesuai/Jelas (bobot 5)
B. Mudah/Bagus/Sesuai/Jelas (bobot 4)
C. Netral (bobot 3)
D. Cukup: Sulit/Bagus/Sesuai/Jelas/ (bobot 2) 
E. Sangat: Sulit/Jelek/TIdak Sesuai/Tidak Jelas (bobot 1)

Tabel 2 merupakan hasil kuisioner UAT yang diberikan kepada 2 responden pengguna.

Tabel 2. Hasil jawaban UAT

\begin{tabular}{|c|c|c|c|c|c|c|c|c|}
\hline \multirow{2}{*}{ No } & \multirow{2}{*}{ Pertanyaan } & \multicolumn{5}{|c|}{ Jawaban } & \multirow{2}{*}{ Jumlah } & \multirow{2}{*}{ Rerata } \\
\hline & & $A \times 5$ & $B \times 4$ & $\mathrm{C} \times 3$ & $D \times 2$ & Ex1 & & \\
\hline 1 & $\begin{array}{l}\text { Apakah tampilan Aplikasi Manajemen } \\
\text { Mess (AMM) ini menarik? }\end{array}$ & 0 & 8 & 0 & 0 & 0 & 8 & 4.0 \\
\hline 2 & $\begin{array}{l}\text { Apakah AMM dapat digunakan dengan } \\
\text { mudah? }\end{array}$ & 5 & 4 & 0 & 0 & 0 & 9 & 4.5 \\
\hline 3 & $\begin{array}{l}\text { Apakah AMM dapat menjadi alat } \\
\text { bantu admin Mess dalam penempatan }\end{array}$ & 10 & 0 & 0 & 0 & 0 & 10 & 5.0 \\
\hline 4 & $\begin{array}{l}\text { Apakah AMM sudah sesuaidengan } \\
\text { usulan awal saat Aplikasi Mess dibuat? }\end{array}$ & 10 & 0 & 0 & 0 & 0 & 10 & 5.0 \\
\hline 5 & $\begin{array}{l}\text { Apakah penempatan karyawan mess } \\
\text { dengan aplikasi dapat terstruktur? }\end{array}$ & 10 & 0 & 0 & 0 & 0 & 10 & 5.0 \\
\hline 6 & $\begin{array}{l}\text { Apakah isi data AMM ini sudah sesuai } \\
\text { dengan data aslinya? }\end{array}$ & 10 & 0 & 0 & 0 & 0 & 10 & 5.0 \\
\hline 7 & $\begin{array}{l}\text { Apakah Password setiap User sudah } \\
\text { Tersembunyi (tidak dapat dilihat oleh } \\
\text { orang lain)? }\end{array}$ & 10 & 0 & 0 & 0 & 0 & 10 & 5.0 \\
\hline
\end{tabular}

\section{SIMPULAN}

Kesimpulan yang dimabil dari pembuatan Aplikasi Manajemen Mes yaitu:

- Telah dibangun dan implementasi Aplikasi Manajemen Mes Berbasis Web, sehingga dapat membantu perusahaan PT. PPA dalam mengelola mes dari memasukkan data karyawan hingga pelaporan berdasarakan tanggal.

- Pengujian Aplikasi Manajemen Mes Berbasis Web menggunakan pengujian Black Box berjalan dengan baik secara fungsional.

- Berdasarkan pengujian UAT, bahwa Aplikasi Manajemen Mes memiliki tampilan menarik, sangat mudah digunakan, sangat membantu relokasi kamar, sangat sesuai dengan desain diusulkan, sangat terorganisir kamar karyawan, sangat sesuai data yang telah dimasukkan dan password dapat disembunyikan sangat sesuai.
- Apabila penambahan sistem atau aplikasi, data dapat dilakukan integrasi data melalui database yang telah dibangun.

\section{UCAPAN TERIMA KASIH}

Penulis menyampaikan terima kasih yang mendalam dan penghargaan kepada:

- Politeknik Negeri Tanah laut, sebagai lembaga penulis.

- PT. PPA Bersedia memberikan arahan dan data selama pembangunan aplikasi.

\section{DAFTAR PUSTAKA}

[1] T. Murnane and K. Reed, "On the effectiveness of mutation analysis as a black box testing technique," in Proceedings of the Australian Software Engineering Conference, ASWEC, 2001, doi: 10.1109/ASWEC.2001.948492.

[2] S. Nidhra and J. Dondeti, "Black Box and White Box Testing Techniques - A Literature Review," Int. J. Embed. Syst. Appl., 2012, doi: 10.5121 ijesa.2012.2204.

[3] M. Setter, "User Acceptance Testing - How To Do It Right!," Usersnap, 2019. [Online]. Available: https://usersnap.com/blog/user-acceptance-testing-right/.

[4] A. N. Sani, M. Susantok, and R. D. Rahayani, "Sistem Reservasi Wisma Berbasis Android di PT. Chevron Pacific Indonesia," J. Aksara Elem., 2017.

[5] A. L. Azhari and R.- Tanone, "Analisis Penerapan Single Page Application Menggunakan Teknologi AJAX dan REST API (Studi Kasus :Sistem Informasi Reservasi Wisma Tamu UKSW)," J. Tek. Inform. dan Sist. Inf., 2017, doi: 10.28932/jutisi.v3i1.577.

[6] H. J. Sitanggang, E. Hernawati, and F. A. Tridalestari, "Aplikasi Reservasi Kamar Wisma Berbasis Web Studi Kasus: Penginapan Imbalo Group Rantau Parapat Sumatera Utara The Home-Based Applications Rooms Reservation Web Case Study: Lodging Group Imbalo Rantau Parapat North Sumatra," -Proceeding Appl. Sci., vol. 3, no. 3, pp. 1331-1342, 2017.

[7] M. S. Rahmawati and A. R. Purnamasari, "Perancangan Sistem Informasi Penginapan Berbasis Dekstop Di Penginapan a2Hay," vol. 4, no. 2, pp. 38-50, 2018.

[8] Amna Zulqadar, "SDLC Waterfall Model: The 6 phases you need to know about," Rezaid, 2019. [Online]. Available: https://rezaid.co.uk/sdlc-waterfall-model/. 